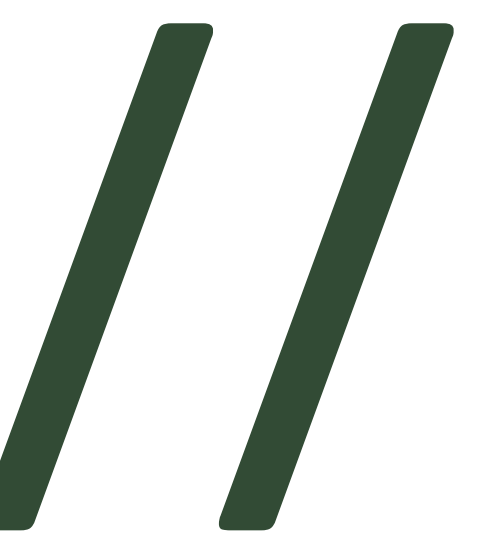

\title{
Que coisas nossas são estas? Música popular, disco e o início do
} cinema sonoro no Brasil ${ }^{1}$ 'Our things'? Popular music, phonograph records and the beginnings of sound film in Brazil

$\bar{l}$ Versões iniciais deste texto foram apresentadas em dois encontros científicos: no Seminário Temático Teoria e Estética do Som no Audiovisual (XVIII Encontro Internacional da Socine - UNIFOR, Fortaleza, CE, 2014) e na conferência Hollywood's Musical Contemporaries and Competitors in the Early Sound Film Era (Universidade de Surrey, Gildford, UK, 2014). Agradeço aos colegas pelas generosas contribuições que obtive em ambos os eventos.

2 Suzana Reck Miranda é graduada em Música (piano) pela UFSM e mestre e doutora em Multimeios (cinema) pela UNICAMP. Docente do Departamento de Artes e Comunicação e do Programa de PósGraduação em Imagem e Som, ambos da UFSCar. E-mail: suzana@ ufscar.br. 
Resumo: Este artigo destaca elementos históricos e estilísticos que cercam o filme Coisas Nossas (1931), apontado como o primeiro longa-metragem musical brasileiro 'inteiramente sincronizado' com o uso do sistema vitaphone. Interessa-nos, sobretudo, o seu repertório musical. Observaremos possíveis ligações dos estilos e dos intérpretes com a dinâmica da indústria fonográfica do período, na tentativa de compreender o que, naquele momento, foi tomado como sendo as "nossas coisas".

Palavras-chave: música no cinema; início do cinema sonoro; música popular brasileira; cinema brasileiro.

Abstract: This paper sets out to underscore the historical and stylistic particularities surrounding the film Coisas Nossas (Our things,1931), which is regarded as the first Brazilian musical feature film, entirely 'in sync' using the vitaphone system. The main focus lies on the characteristics of the film's musical repertoire and its possible connections to the Brazilian recording industry. Our aim is to understand what the so-called 'our things' were supposed to be, at that point in time.

Key words: film music; early sound films; Brazilian popular music; Brazilian cinema. 
Coisas Nossas (Wallace Downey, 1931) foi o primeiro longa-metragem brasileiro ‘inteiramente sincronizado’ com o uso do sistema vitaphone a conter não apenas música, mas também vozes e ruídos³. Inspirado em revistas musicais norteamericanas, como Hollywood Revue (Charles Reisner, 1929), o filme, que não tinha um enredo específico (como fio condutor), apresentava números musicais e esquetes cômicas, ambos com artistas populares que já circulavam pelo teatro, pelo rádio e no mercado fonográfico local. Integrante do rol de filmes cujos originais e cópias se perderam, seus vestígios encontram-se nas notas publicadas na imprensa da época e na bibliografia existente sobre a História do Cinema Brasileiro. Graças à descoberta, em 1995, de exemplares dos discos de sua trilha sonora no acervo do Museu de Comunicação Social Hipólito José da Costa (Porto Alegre, RS), é possível também, como nos aponta Fernando Morais da Costa (COSTA, 2008, p. 108-9) especular sobre o filme a partir de sua porção sonora.

Neste artigo, o foco principal reside nas características do repertório musical do filme e nas possíveis ligações com a indústria do disco no Brasil naquele momento. Portanto, embora a relação do início do cinema sonoro com o mercado fonográfico seja recorrente na História do Cinema Mundial, nosso objetivo é observar quais são as particularidades que ocorreram no contexto brasileiro e, principalmente, compreender o que, na época, foi tomado como sendo as "nossas coisas" em um cenário no qual, além de enfrentar o domínio hollywoodiano, era preciso investir em uma identidade nacional que transpusesse as diversidades regionais. Afinal, não podemos ignorar que a recém-instaurada Segunda República (1930-37), presidida por Getúlio Vargas, trazia em seu bojo um percurso - iniciado pelas elites intelectuais nos anos 1910 - marcado pela construção da tal identidade nacional. Neste sentido, portanto, vale destacar que o rádio e o cinema serão vistos como espaços fundamentais para consolidar tal pretensão ${ }^{4}$.

De todo modo, como nos esclarece Carlos Roberto de Souza, Coisas Nossas foi uma experiência peculiar dentro do contexto cinematográfico do período. Seus idealizadores estavam originariamente ligados à indústria do disco e de aparelhos elétricos e não ao cinema (SOUZA, 2007, p. 33). A produção ficou a cargo da Byington e Cia, importante empresa brasileira que atuava no setor elétrico, na importação e

3 O primeiro uso do sistema vitaphone em um longa-metragem brasileiro ocorreu em Mulher (Octávio Gabus Mendes, 1931), uma produção da Cinédia lançada um mês antes do Coisas Nossas. No entanto, este filme foi concebido para ter apenas a música sincronizada em disco, ou seja, não foi idealizado para ser um 'filme falado'. Maiores detalhes podem ser encontrados em COSTA, 2013.

4 Muitos autores têm trabalhado a relação entre cultura popular e Estado nos anos 1930, no Brasil. Destacamos, aqui alguns exemplos: DA MATTA, 1981; HERSCHMANN; PEREIRA, 1994; ORTIZ, 1985; SIMIS, 1996; VIANNA, 1995. 
comercialização de inúmeros equipamentos, no rádio e que representava a Columbia Phonograph Company no Brasil. O norte-americano Wallace Downey, que na época era o supervisor artístico da Columbia em São Paulo, assina a direção. Downey foi peça-chave na instalação da filial da Columbia em São Paulo e, segundo Freire (FREIRE, 2013a, p. 121-2), o norte-americano foi enviado ao Brasil, em 1928, para este fim, já que a chegada da gravação elétrica fomentou a expansão da indústria fonográfica local e outras empresas estrangeiras estavam entrando no mercado brasileiro. A Byington e Cia., comandada pelo também norte-americano - mas naturalizado brasileiro - Albert J. Byington, com apoio do filho Alberto Byington Jr., associou-se ao empreendimento.

Freire acrescenta que, antes de apostar na produção de filmes, a Byington e Cia. investiu na fabricação de projetores sonoros para o circuito exibidor brasileiro, impulsionada pelo sucesso que o longa-metragem Acabaram-se os Otários (1929), de Luiz de Barros, obteve (FREIRE, 2013a, p.124). Vale lembrar que este filme foi, de fato, o primeiro longa-metragem sonoro do cinema brasileiro e tal façanha só foi possível porque Barros e seus sócios desenvolveram um sistema de projeção sonora - o Sincrocinex - que, ainda de acordo com Freire, consistia em uma "moderna vitrola ligada à auto-falantes". Os discos de Acabaram-se os Otários, portanto, eram os mesmos usados na indústria fonográfica, de 78 rpm. Já o sistema que a Byington e Cia. desenvolveu chamava-se Fonocinex e chegou a ser comercializado em vários estados brasileiros. O filme Coisas Nossas, embora tenha usado o sistema vitaphone, acabou servindo para "enaltecer" a aparelhagem por eles produzida (FREIRE, 2013a, p. 128). De qualquer modo, a nosso ver, o filme também ajudou a promover outro investimento da família Byington: os artistas brasileiros com contratos pela Columbia.

\section{Downey e as nossas coisas}

Quando desembarcou no Brasil, Wallace Downey já era um veterano no ramo das gravações musicais. Segundo nota publicada na Variety, em 01 de setembro 1922, ele, que nesta época tinha 20 anos de idade, havia acabado de se demitir da Cameo Records, em Nova York, onde comandava o laboratório de gravação, para investir neste ramo por conta própria. Jairo Severiano menciona que quando Downey foi enviado a São Paulo, ocupava funções importantes na Columbia norte-americana e que, no Brasil, mesmo sem ainda dominar o português, era ele quem estava à frente nas negociações com os artistas locais (SEVERIANO, 1997, p.39). Sua eficiência pode ser dimensionada pela produção, pois até o final de julho de 1929, a divisão 
brasileira comandada pela Byington e Cia. já havia produzido cerca de vinte e cinco discos com o novo sistema elétrico. Boa parte dos artistas gravados, de acordo com o jornalista Aramis Millarch', estabeleceram contratos exclusivos com a Columbia (MILLARCH, 1991). Alguns destes pioneiros como Paraguassú, Batista Júnior e Jaime Redondo formariam, juntamente com futuras contratações, a constelação de estrelas do filme Coisas Nossas.

As atrações contidas no filme foram parcialmente descritas na imprensa da época e, por vezes, acompanhadas de imagens (fotografias e cartazes publicitários). Conforme já dissemos, estes e outros textos (sobre o cinema brasileiro) foram, durante um bom tempo, as referências às quais os pesquisadores recorriam para recuperar seus rastros. Costa reforça que a descoberta dos discos (vitaphone) permitiu ratificar e/ou contestar os dados existentes (COSTA, 2008, p. 108).

Ao confrontarmos estes materiais, uma das primeiras constatações possíveis é a de que, se levarmos em conta todas as atrações descritas (especialmente nos jornais e revistas da época), talvez o número de discos estimado pelo museu de Porto Alegre não esteja correto. O material impresso que acompanha o $\mathrm{CD}^{6}$ (com as gravações restauradas) informa que Coisas Nossas teria oito discos dos quais sete foram parcialmente resgatados e disponibilizados. No entanto, apenas um disco a mais não conseguiria conter as músicas, os números com dança e os esquetes cômicos (citados em fontes diversas) que não figuram nas gravações preservadas. Como algumas das atrações que ficaram de fora foram descritas em diferentes materiais, não há como especular sobre o filme sem enfrentar estes paradoxos.

De acordo com os materiais consultados, supomos que o casting era assim composto: os atores Procópio Ferreira e Genésio Arruda, líderes de importantes companhias teatrais; a dupla sertaneja Calazans e Rangel (também conhecida como Jararaca e Ratinho); o ator cômico, compositor e cantor Batista Júnior (João Batista de Oliveira Júnior); o artista circense Alcebíades Pereira, considerado um dos clownsbrancos mais importantes do circo brasileiro; os cantores Jaime Redondo, Paraguassú (Roque Ricciardi), Arnaldo Pescuma e Pilé (Manoel dos Santos); as cantoras Helena Pinto de Carvalho, Stefana de Macedo e Zezé Lara; a atriz e dançarina Corita Cunha (Cora Acuña), o pianista e maestro da Orquestra Jazz Columbia Gaó (Odmar Amaral Gurgel); o multi-instrumentista Zezinho (José do Patrocínio Oliveira) e seu conjunto regional (com vários integrantes que também eram da Jazz Columbia);

5 Disponível em <http://www.millarch.org/artigo/continental-sua-historia-gravada-fundo-dentro-da-mpb >. Acesso em 09 ago. 2015.

6 Trata-se, na verdade, de uma edição comemorativa aos cem anos do cinema - do Museu de Comunicação Social Hipólito José da Costa, de Porto Alegre, RS - que contém um pequeno livro e um CD. Antônio Jesus Pfeil é o autor dos textos explicativos e o responsável pelo projeto de restauração sonora. O CD é que está incluído neste material (PFEIL, A. J., 1995). 
o trompetista e regente Napoleão Tavares que, como Gáo e Zezinho, integrava e organizava diferentes formações orquestrais para as gravações da Columbia). Estes 17 nomes tinham seus rostos estampados (dentro de estrelas) em alguns materiais gráficos sobre o filme que circularam na época. Outras participações citadas (por diferentes meios que as atestam) são do poeta paulistano Guilherme de Almeida, da atriz Nenê Biolo, da cantora Alzirinha Camargo e do comediante Príncipe Maluco (João Petrillo), nome conhecido nos cassinos e no teatro de revista brasileiro ${ }^{7}$.

A maioria destes artistas era paulista e/ou atuava em São Paulo com regularidade, principalmente no rádio. Arruda, em especial, era um nome de destaque no teatro de revista. Quanto aos músicos, ou já tinham contratos com a Columbia, ou passaram a ter, a partir das filmagens. Alguns deles, como Paraguassú, apresentavam-se com frequência em espetáculos de variedades. Sendo assim, estas são basicamente as "nossas coisas" que Byington e Downey elegeram para integrar aquele que viria a ser o primeiro "filmusical genuinamente brasileiro".

\section{O repertório musical}

Embora o repertório de Coisas Nossas possa ser inicialmente associado a características regionais, o filme foi bem recebido em vários estados brasileiros e teve uma temporada muito bem-sucedida no Rio de Janeiro que, naquele momento, era a Capital Federal do país. Vale lembrar que, neste período, o samba, mesmo já sendo um gênero musical urbano proeminente (não apenas no Rio de Janeiro), ainda não estava ligado à aura de 'unidade nacional' que o cercará a partir de meados nos anos 1930, na esteira da política econômica nacionalista do então presidente Getúlio Vargas, como já destacado inicialmente neste texto. Resumidamente, podemos dizer que desde o final da década de 1910 havia, no Brasil, debates integrados a um 'projeto modernista' que envolviam a valorização de uma cultura rural como elemento importante para a construção de uma cultura nacional e genuína. Ritmos musicais interioranos e do nordeste brasileiro (emboladas, cocos, batuques, cateretês, cururus...) são valorizados pelos intelectuais e artistas e passam a influenciar tanto as composições eruditas quanto as populares urbanas.

\footnotetext{
7 Outros nomes foram citados esporadicamente, como: Francisco Alves, Dircinha Batista, a dupla Alvarenga e Ranchinho e o palhaço Piolin. Dircinha, mesmo tendo na época nove anos de idade, como era filha de Batista Júnior e já havia gravado um disco na Columbia, talvez tenha tido uma pequena participação. Francisco Alves, cantor muito famoso, tinha contrato exclusivo com a Odeon/Parlophon, fato que torna improvável a sua participação em Coisas Nossas, a não ser que estivesse devidamente disfarçado. Quanto a dupla Alvarenga e Ranchinho que, de acordo com seus biógrafos, foi formada a partir de 1933, sua presença é pouco provável. Já o famoso palhaço Piolin, embora tenha de fato atuado em dupla com Alcebíades Pereira, não deve ter participado. Pelo menos é o que reforça o esquete contido nos discos preservados, pois quem contracena com Alcebíades é o seu filho Albano Pereira Neto, o Albaninho.
} 
A cultura sertaneja, por exemplo, já transitava no teatro de revista carioca desde a década de 1910 e, em São Paulo, mesclou-se com as tradições caipiras (do homem do campo das regiões sudeste e centro-oeste). Vince de Moraes aponta o surgimento de canções com "melodias caboclas" entres os compositores paulistas ainda nos anos 1910, bem como a circulação de espetáculos com violeiros, "causos" e anedotas oriundas do universo caipira e sertanejo, cujo ponto alto deu-se na caravana do jornalista Cornélio Pires ${ }^{8}$ que, no final da década de 1920, excursionou por todo o interior paulista (MORAES, 2000, p. 5). Os nordestinos Jararaca e Ratinho, por exemplo, eram conhecidos mesmo antes de excursionarem nesta caravana: faziam sucesso nas revistas teatrais cariocas e, desde 1924 gravavam discos na Odeon?.

No momento em que Coisas Nossas foi gerado, portanto, o Brasil possuía um cenário musical bem fragmentado e com características variadas. O rádio e a indústria do disco estavam em plena expansão, o que representava novas formas de circulação para a música popular, que décadas antes ocorria apenas nos teatros, circos e outros estabelecimentos de espetáculo. Vince de Moraes destaca ainda a “profissionalização" de grande quantidade de músicos neste período, que passou a integrar os conjuntos musicais atuantes no rádio e nas gravadoras, ambientes nos quais sambas, choros, canções, toadas, modas de viola convivem lado a lado com outros gêneros 'estrangeiros', como o tango e o foxtrote (MORAES, 2000, p. 12-14).

O rádio teve um papel crucial no estabelecimento de um star system de artistas brasileiros e tal fato, além de contribuir com os interesses comerciais das gravadoras locais, foi um dispositivo estratégico, dentro da lógica do Estado, na disseminação de uma desejada integração nacional, uma vez que a música é uma expressão de extrema importância na constituição da identidade cultural. No entanto, como o debate sobre os processos políticos e culturais envolvidos na ideia de brasilidade é extenso, dado os limites deste texto, nosso objetivo, ao mencionamos esta questão, é destacar que entre os artistas da época o nacional e o popular também eram temas recorrentes. Por este motivo, alguns compositores e intérpretes mais engajados com os ritmos brasileiros sentiam certo desconforto em observar que em muitas gravadoras havia estrangeiros no comando, tanto na produção executiva quanto musical. Voltaremos a este tema logo mais.

Mas, se o desenho da relação entre as mídias daquele momento já é hoje mais conhecido, o mesmo não se pode dizer em relação a certas produções. No caso de Coisas Nossas, o que temos para observar concretamente, como dito, são as atrações musicais. Aqui, levaremos em conta o repertório musical contido nos discos

8 Sobre as diversas atividades de Cornélio Pires, indicamos as seguintes leituras: FREIRE, 2013b, p. $104-$ 128 e SCHVARZMAN, 2011, p. 46-64.

9 A gravadora Odeon, no Brasil, atuava no Rio de Janeiro. 
preservados e o apresentaremos conforme a sequência em que estão dispostos no CD, embora esta ordem não corresponda a muitas das descrições que encontramos. Também não vamos considerar nesta análise as curtas intervenções musicais dos esquetes cômicos. Sendo assim, a primeira peça musical - apresentada no referido material - é instrumental e não foi oralmente identificada. Possui um caráter de abertura e lembra uma marcha circense, pois inicia com uma breve fanfarra e, em seguida, assume um compasso 4/4 com andamento rápido. Após, é a vez da primeira canção, que é anunciada por uma espécie de mestre de cerimônias. Helena Pinto de Carvalho interpreta Esse jeitinho que você tem ${ }^{10}$, uma toada de Marcelo Tupinambá, com o acompanhamento de Gaó ao piano e de uma pequena formação orquestral. Tupinambá era o pseudônimo de Fernando Álvares Lobo, músico com formação erudita e prestigiado entre os intelectuais. Suas canções populares eram admiradas por conterem 'elementos caboclos'.

A próxima atração musical, também não oralmente identificada na gravação, contém duas canções de caráter rural, cujas letras remetem ao universo caboclo e interiorano. A primeira, com andamento rápido, é interpretada por vozes masculinas em coro e a segunda, uma toada, traz uma voz feminina como destaque. Esta primeira canção é, na verdade, uma versão acaipirada de uma tradicional marchinha de carnaval chamada Juracy, composta em 1931 por Lamartine Babo e Vantuil de Carvalho ${ }^{11}$. Esta versão retirou tanto da letra quanto da música os possíveis elementos carnavalescos e adaptou-os ao cotidiano e à sonoridade do meio rural. $\mathrm{O}$ pierrô (da letra) foi transformado em caboclo e os metais e percussão (da marcha) foram substituídos por uma formação típica de um regional (violino, violão, banjo, flauta, clarinete, acordeão). Já a toada, que no filme é interpretada por Zezé Lara, é uma composição de Marcelo Tupinambá denominada Tarde Sertaneja ${ }^{12}$ que, de fato, foi inspirada em uma tarde no campo e no universo caipira.

Em seguida, é a vez de tico-tico do fubá, conhecido choro de Zequinha de Abreu, em versão instrumental. É provável que seja uma interpretação da Orquestra Jazz Columbia comandada por Gaó. Supomos isto porque no disco ${ }^{13}$ que a Columbia

10 As gravações em vitaphone do Coisas Nossas não estão disponíveis online. No entanto, arquivos com várias das canções executadas no filme (extraídos de discos de $78 \mathrm{rpm}$ gravados e comercializados pela Columbia) podem ser acessados no banco de dados do Instituto Moreira Salles. Helena Pinto de Carvalho gravou esta mesma toada em 1931 (Disponível em < http://acervo.ims.com.br/index.asp?codigo $\underline{\text { sophia }=6768}>$. Acesso em 09 ago. 2015).

11 Até o momento, não localizamos uma gravação comercial desta versão caipirada (que foi feita para o filme). Já a marchinha original está disponível em $<$ http://acervo.ims.com.br/index.asp?codigo_ $\underline{\text { sophia }=13399}>$. Acesso em 09 ago. 2015.

12 A versão lançada em $78 \mathrm{rpm}$ pela Columbia pode ser ouvida em: < http://acervo.ims.com.br/index. asp?codigo sophia $=15812>$. Acesso em 09 ago. 2015.

13 Disponível em < http://acervo.ims.com.br/index.asp?codigo sophia=1228 > . Acesso em 09 ago. 2015. 
lançou em 1931 e que foi a primeira gravação deste choro (composto por Abreu em 1917) consta que a interpretação é da Orquestra Colbaz, conjunto instrumental formado por Gaó e que contava com Zezinho no violino e no banjo. Após, surge uma embolada interpretada por vozes masculinas e por um conjunto instrumental semelhante ao que supomos ser o Regional comandado por Zezinho. As estrofes são cantadas por uma única voz masculina e o estribilho, por um pequeno coro. A letra, com dialeto caipira, conta uma engraçada história sobre um galo. Acreditamos tratarse da embolada galo danado, gravada por Jararaca (Calazans) na Columbia em 1930 (78 rpm, $\mathrm{n}^{\circ} 5.170$ ), fato que nos leva também a supor que a voz masculina que se destaca nesta gravação seja a do próprio Calazans.

O próximo número musical ocorre durante um esquete cômico que se passa em uma barbearia. Alguém pede a Paraguassú que interprete a valsa-canção Nunca Mais. O músico reluta, mas acaba cedendo. Canta e toca ao violão a peça solicitada, cuja autoria é atribuída a Eduardo dos Santos e Gutemberg Cruz, de acordo com as informações do disco n ${ }^{0} 5.091$, gravado ${ }^{14}$ por ele mesmo na Columbia, em 1929. A canção que segue não é anunciada, mas identificamos que é Saudade, na voz de Jaime Redondo. A imprensa ${ }^{15}$ da época noticiou que Redondo cantava esta conhecida toada para Nenê Biolo, em um quadro chamado "noites gaúchas". Curiosamente, a canção ${ }^{16}$ é uma 'versão brasileira' de uma melodia do diretor e compositor norteamericano Victor Schertzinger.

Na sequência, Sebastião Arruda declama Três Lágrimas, poema atribuído a Campos Negreiros, conforme consta em uma das gravações do famoso "selo vermelho" da série Cornélio Pires ${ }^{17}$. A seguir, surge uma paródia da canção de Redondo. Uma voz desleixada, com sotaque caipira, canta acompanhada de um violão. Uma segunda voz, também engraçada, acrescenta comentários ao final de algumas frases. Tais características nos levam a imaginar que a interpretação desta paródia esteja a cargo de uma dupla sertaneja. Stefana de Macedo é quem interpreta

14 Disponível em < h http://acervo.ims.com.br/index.asp?codigo sophia=13770 $>$. Acesso em 09 ago. 2015.

15 Exemplos: "Coisas Nossas, um film que promete”. Correio da Manhã, Rio de Janeiro, 27 nov. 1931, p. 8 e "O cinema fallado no Brasil". Jornal do Brasil, Rio de Janeiro, l dez. 1931, p. 17.

16 A versão gravada na Columbia está disponível em <http://acervo.ims.com.br/index.asp?codigo_ sophia $=6375>$. Acesso em 09 ago. 2015.

17 Segundo J.L.Ferreti, no final de 1928, o jornalista Cornélio Pires foi até a Columbia interessado em gravar a anedotas e modas de viola caipiras. Wallace Downey interessou-se pelo tema, mas o proprietário Byington Jr., que era quem dava a palavra final, não quis investir no projeto por achá-lo pouco lucrativo. Cornélio Pires não desistiu da ideia e, com dinheiro emprestado, pagou pelos custos da gravação e exigiu que a Columbia criasse um selo de cor diferente para o rótulo, por isso a cor vermelha. Após, com o objetivo de recuperar o montante investido, ele montou a já mencionada "caravana" de artistas caipiras e empreendeu as excursões pelo interior paulista (para que se apresentassem e vendessem os discos). $\mathrm{O}$ sucesso foi tão grande que Byington acabou propondo uma espécie de associação a Cornélio e outras séries do então bem sucedido selo foram produzidas (FERRETI, 1985). 
(e assina) os arranjos das duas próximas músicas: Bambalelê e Batuque. Ambas são oriundas da cultura oral brasileira e ela mesma já as havia gravado na Columbia, em 1929, nos discos $n^{\circ} 5067$ e $n^{\circ} 5093^{18}$, respectivamente. Cabe frisar que Stefana era uma cantora respeitada também no meio intelectual, reconhecida por pesquisar e recolher canções regionais, principalmente nordestinas.

$\mathrm{Na}$ última parte do CD, Jararaca e Ratinho apresentam um diálogo humorístico. Enquanto Jararaca (Calazans) dedilha seu violão, Ratinho (Rangel) chega e os dois iniciam um diálogo repleto de anedotas. Quando Ratinho fala em ir embora, Jararaca diz que quer tocar um "samba” que fez em sua homenagem. Neste momento, a dupla, na verdade, canta uma embolada - coco do mato - que já havia sido por eles registrada na Columbia, em 1930. ${ }^{19}$ Finalizando a sequência, Ratinho pede a Jararaca que o acompanhe em um chorinho, enquanto toca as primeiras notas no saxofone. Ratinho era um exímio saxofonista e compôs vários choros. Este que é executado em Coisas Nossas parece ser uma variação daquele que soa no final do número humorístico Cadê tempo, gravado no lado B do mesmo disco que contém a embolada coco do mato.

Das onze músicas que integram os sete discos parcialmente recuperados, temos: uma abertura circense, uma marcha 'caipira', três toadas, dois choros, uma canção, duas peças de tradição oral e duas emboladas. Sabemos que o filme continha outros números com música, um dos quais era com o samba Não me Perguntes, de Joubert de Carvalho, interpretado por Arnaldo Pescuma. No entanto, chama-nos a atenção o fato de que, no repertório que nos foi possível ouvir, há o predomínio de sonoridades e ritmos ligados ao universo rural. Antes de apresentarmos uma possível hipótese em relação a esta característica, retomaremos a já citada presença estrangeira nas gravadoras brasileiras.

\section{Yes, nós temos discos}

Conforme já dissemos, no começo dos anos 1930, o cenário musical no Brasil era variado e estava em plena expansão. Severiano destaca que a chegada do rádio, da gravação elétrica e do 'cinema falado ${ }^{20}$ ' impulsiona sobremaneira a música popular brasileira, tanto no que diz respeito aos meios de circulação quanto

18 Disponível em < http://acervo.ims.com.br/index.asp?codigo_sophia=6418 >. Acesso em 09 ago. 2015.

19 Disponível em < http://acervo.ims.com.br/index.asp?codigo_sophia=6460 > . Acesso em 09 ago. 2015.

20 Apesar de reconhecermos que a discussão sobre a entrada dos talkies no Brasil, neste período, ampliaria a percepção do cenário em que Coisas Nossas está inserido, avaliamos que, em função do recorte definido, a inserção deste debate traria o risco de uma possível dispersão em relação às principais questões que norteiam este texto. 
às inovações estéticas, uma vez que o contato com elementos culturais distintos se intensificou. Tal fenômeno resultou também no crescimento da influência de sonoridades estrangeiras nas criações musicais urbanas (SEVERIANO, 2008, p. 96103). Obviamente que estas trocas culturais são complexas e não exclusivas do meio musical, perpassando todas as produções artísticas do período. No entanto, assim como para Severiano, interessa-nos especificamente observar o meio musical. Ou seja, os músicos, que antes tinham o teatro de revista e o circo como os espaços mais importantes para a divulgação dos seus trabalhos, encontram-se diante de novas oportunidades. Para o autor, este é o começo da primeira grande fase da música popular urbana, a chamada época de ouro (1929-1945), na qual muitos artistas talentosos despontam.

Tinhorão acrescenta que a pequena gravadora Brunswick ${ }^{21}$ foi a primeira a apostar majoritariamente em músicas consideradas tipicamente brasileiras (maxixes, choros, emboladas, sambas, marchas de carnaval, entre outras). Não que as maiores (como a Odeon e a Victor) não mantivessem altos índices de gravações similares, mas ritmos de outros países detinham uma boa fatia das produções. O historiador também ressalta que, no Rio de Janeiro, a aproximação entre estilos musicais da classe média (como o choro) e das classes mais baixas (como o samba) impulsionou o surgimento dos Conjuntos Regionais, que passaram a representar uma espécie de síntese da música urbana brasileira (TINHORÃO, 1998, p. 295-298).

No entanto, é preciso reforçar que nossa indústria fonográfica era dominada por corporações estrangeiras que, como bem apontou Bryan McCann, não trouxeram para o Brasil apenas capital e tecnologia, mas também influências culturais marcantes (McCANN, 2004, p. 138). A sonoridade dos Regionais muitas vezes foi transposta para formações orquestrais que destacavam o naipe dos sopros, numa clara referência às jazz bands norte-americanas. Tal prática, extensiva também às emissoras de rádio, nem sempre era bem vista entre músicos e/ou críticos. Por exemplo, em 1928, o crítico da revista Phono-Arte Cruz Cordeiro atacou duramente os 'estrangeirismos' das gravações de Pixinguinha (CABRAL, 1997), que era o regente e arranjador da Victor. Quem comandava esta gravadora, na época, era o estadunidense Leslie Evans que, como seu conterrâneo Downey, fora alvo de desavenças, já que ambos eram tidos como 'americanizadores' da nossa música.

Embora criticado no meio fonográfico, isso não impediu que a Byington e Cia. confiasse a Downey a direção de Coisas Nossas. Ao contrário, o filme, de um modo geral, foi bem recebido no meio cinematográfico e obteve um marcante sucesso de bilheteria, chegando até mesmo, como bem apontou a pesquisadora Joice

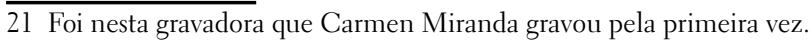


Scavone Costa, a arrastar "pela primeira vez na história um presidente da República para ver um filme brasileiro em uma sessão pública” (COSTA, 2013, pg. 85).

Acreditamos que a escolha do repertório tenha ajudado a relativizar o fato de que um estrangeiro estava encabeçando o agenciamento das 'nossas coisas'. Alberto Byington Jr. e Downey souberam selecionar o que, naquele momento, na Columbia, tinha potencial para ser reconhecido como típico do Brasil. Ou seja, ao invés de escalarem Simon Bountman, maestro russo atuante no Rio de Janeiro e que volta e meia regia a Orquestra Columbia em gravações, principalmente de marchinhas carnavalescas, preferiram Gaó, o “mágico do piano” de São Paulo que, como Zezinho, não apenas estava ligado à Orquestra Colbaz, conjunto Regional que gravou vários choros, mas também arranjou inúmeras toadas, emboladas, cateretês, e mais outros tantos ritmos rurais que a Columbia gravou, desde o início de suas atividades em solo brasileiro.

Outra estratégia que chamou nossa atenção foi o acaipiramento da marchinha carnavalesca Juracy, cuja melodia inicial, por sinal, assemelha-se ao refrão de Piccadilly ${ }^{22}$ (1921), canção de sucesso do music hall britânico ${ }^{23}$. No entanto, a sonoridade rural, de certa forma, contribuiu para disfarçar tal semelhança, façanha que, em nossa opinião, é mais difícil para a marchinha original24. Deste modo, a presença dominante de ritmos e melodias interioranas parece desempenhar, em Coisas Nossas, um duplo papel: o de reforçar uma possível aura de autenticidade e o de disfarçar as trocas multiculturais.

O samba, portanto, não foi dominante na primeira bem-sucedida experiência do cinema sonoro brasileiro. Fato compreensível, primeiro, como já destacado, pelas próprias condições históricas de um país ainda bastante rural. E, segundo, porque o próprio processo de reconhecimento do samba como o símbolo maior da identidade nacional brasileira era muito inicial neste período e, basicamente, restrito à elite intelectual e artística, ou seja, ainda ignorado pelo Estado ${ }^{25}$. Mas, em breve, o quadro

22 Composição de Bruce Sievier, Walter Williams e Paul A. Morande - que ganhou fama mundial na interpretação de Hetty King (Winifred Emms, 1883-1972).

23 Agradeço à Elaine Burrows por ter me apontado esta similaridade.

24 Conforme nos lembra Severiano, a marchinha carnavalesca brasileira foi desenvolvida por músicos ligados ao teatro de revista carioca e possui forte influência de ritmos estrangeiros (amplamente usados nas revistas musicais norte-americanas e europeias) como a marcha portuguesa, o charleston, o one-step, a polca (SEVERIANO, 2008, p.77).

25 Um indicativo ou evidência deste interesse do Estado pela região rural, incluindo a sua música, podem ser os curtas produzidos no Instituto Nacional do Cinema Educativo (INCE), criado por Roquette Pinto em 1936, com apoio do então ministro da Educação e Saúde, Gustavo Capanema e total aprovação de Getúlio Vargas. O esforço de se priorizar tais aspectos como identitários do país fica ainda mais evidente com a série "Brasilianas", de Humberto Mauro, produzida de 1945 a 1964, que foca canções populares apresentadas em curtas-metragens que reafirmam os aspectos bucólicos e envolventes do mundo rural (Ver SCHVARZMAN, 2004). 
será outro, pois, como nos esclarece Hermano Vianna, a miscigenação passa a ser amplamente aceita como uma marca de autenticidade brasileira, o que faz com que o samba - a música das comunidades urbanas negras - seja prontamente vinculado a tal imaginário. Esta aceitação decorre principalmente de dois movimentos: de um lado, através do Estado que, após a Revolução de 1930 “tornou semi-oficial a política da miscigenação" e, de outro, via a disseminação dos ideais de Gilberto Freyre, decorrentes da publicação de Casa Grande e Senzala em 1933 (VIANNA, 1995, p. 73). Ainda conforme este autor (p.154), foi este discurso em torno da mestiçagem que tornou possível, por exemplo, o patrocínio do Estado aos desfiles de escolas de samba, a partir de meados dos anos 1930.

Assim, não é difícil compreender porque o carnaval e o samba serão as estrelas máximas dos próximos sucessos de bilheteria do cinema brasileiro que, aliás, novamente terão Wallace Downey participando da 'comissão de frente'. Isso porque, apesar de manter a atuação na indústria da música como sua principal atividade, ele tornou-se um nome de destaque, também, na produção de filmes brasileiros. Tanto que seu envolvimento foi determinante para perpetuar por aqui o estilo das revistas musicais norte-americanas, cuja temática passou a ser o carnaval e o samba ${ }^{26}$. E, se vale aqui alguma especulação, talvez Coisas Nossas tenha sido fundamental para que o norte-americano tenha participado desta trilha. De todo modo, o que hoje é possível afirmar é que a porção sonora do filme, resgatada após tantos anos, permite que muitos dos equívocos em relação às informações sobre o Coisas Nossas possam ser, enfim, parcialmente elucidados. Uma situação que, esperamos, deve reverberar nos diversos erros que ainda persistem sobre o filme, como os que circulam em plataformas interativas como a internet ${ }^{27}$.

26 Por exemplo, em associação com a produtora carioca Cinédia, de Adhemar Gonzaga, produziu os musicais Alô, Alô Brasil (1935), no qual também assina a direção, e Alô Alô Carnaval (1936), ambos com números de Carmen Miranda, estrela em plena ascensão. O sucesso comercial destes títulos o levou novamente a uma aliança com Alberto Byington Jr. Dentre os musicais produzidos pela dupla estão os da famosa "trilogia das frutas tropicais": Banana da terra (1938); Laranja da China (1939) e Abacaxi Azul (1943), sendo este último também por ele dirigido e feito em coprodução com a Cinédia. Maiores informações sobre suas atividades cinematográficas podem ser encontradas em CASTRO, 2005 e em RAMOS, F.; MIRANDA, 2012.

27 A título de exemplo, no Youtube há vários links para uma curta sequência em que o "Bando de Tangarás" - do qual fazia parte, entre outros importantes artistas, Noel Rosa -, interpreta "Vamos Fallá do Norte". Num deles, online desde 03/04/2009 (ver: $<$ https://www.youtube.com/watch?v=R-CxZImYd2M >. Acesso em 09 ago. 2015), há um texto que erroneamente identifica tal imagem como pertencente ao Coisas Nossas de Downey. No entanto, trata-se de uma filmagem do diretor italiano Paulo Benedetti, feita em 1929, no intuito de ser sincronizada posteriormente com uma gravação em disco (Parlophon, 78 rpm) da referida música (ver: $<$ http://wwwl.folha.uol.com.br/fsp/1994/8/09/ilustrada/6.html $>$ e $<$ https://www. voutube.com/watch?v=EXaz5f70eq4 $>$. Acesso em 09 ago. 2015). 


\section{Referências Bibliográficas}

CABRAL, S. Pixinguinha, vida e obra. Rio de Janeiro: Lumiar, 1997.

CASTRO, R. Carmem: uma biografia. São Paulo: Cia. das Letras, 2005.

COSTA, F. M. O Som no Cinema Brasileiro. Rio de Janeiro: 7 Letras, 2008.

COSTA, J. S. Mulher: A trajetória do som do primeiro longa-metragem synchronizado da Cinédia. Dissertação (Mestrado). Universidade Federal Fluminense, Niterói RJ, 2013.

DA MATTA, R. Carnavais, malandros e heróis. Para uma sociologia do dilema brasileiro. Rio de Janeiro: Zahar, 1981.

FERRETI, J. L. Capitão Furtado: viola caipira ou sertaneja?. Rio de Janeiro: Funarte, 1985.

FREIRE, R. de L. "Da geração de eletricidade aos divertimentos elétricos: a trajetória empresarial de Alberto Byington Jr. antes da produção de filmes". Estudos Históricos. Rio de Janeiro, vol. 26, n 51, p. 113-131, janeiro-junho de 2013a.

"Acabaram-se os otários: compreendendo o primeiro longametragem brasileiro sonoro". Rebeca, v. 3, 2013b, p. 104-128.

HERSCHMANN, M.; PEREIRA, C. A. M. (orgs). A invenção do Brasil moderno. Rio de Janeiro: Rocco, 1994.

McCANN, B. Hello, Hello Brazil: Popular music in the making of modern Brazil. Durham: Duke University Press, 2004.

MILLARCH, A. "Continental e a sua história gravada fundo dentro da MPB". O Estado do Paraná. Curitiba, 17 de março de 1991. Disponível em < http://www. millarch.org/artigo/continental-sua-historia-gravada-fundo-dentro-da-mpb > Acesso em 09 ago. 2015.

MORAES, J. G. V. de. "Polifonia na metrópole: história e música popular em São Paulo". Tempo, Rio de Janeiro, no 10, p.01-24, dezembro de 2000. Disponível em $<$ http://www.historia.uff.br/tempo/artigos_dossie/artg10-3.pdf>. Acesso em 09 ago. 2015.

ORTIZ, R. Cultura Brasileira e identidade nacional. São Paulo: Brasiliense, 1985. PFEIL, A. J. Vozes do primeiro musical brasileiro: Coisas Nossas. Porto Alegre: Corag, 1995. [Esta publicação contém também um CD, com sete faixas, nas quais estão distribuídas as gravações do filme Coisas Nossas que foram parcialmente restauradas dos discos vitaphone originais].

RAMOS, F. e MIRANDA, L. F. Enciclopédia do Cinema Brasileiro. São Paulo: Senac, 2012 ( $3^{\mathrm{a}} \mathrm{Ed}$.). 
SCHVARZMAN, S. “Travelogue e Cavação no Brasil Pitoresco de Cornélio Pires”. In: PAIVA, S. e SCHVARZMAN, S. (orgs.). Viagem ao Cinema Silencioso do Brasil. Rio de Janeiro: Editorial Azougue, 2011, p. 46-64.

Humberto Mauro e as imagens do Brasil. São Paulo: Unesp, 2004.

SEVERIANO, J. Yes, nós temos Braguinha. Rio de Janeiro: Funarte, 1987.

Uma história da música popular brasileira: das origens à modemidade. São

Paulo: Editora 34, 2008.

SIMIS, A. Estado e Cinema no Brasil. São Paulo: Annablume, 1996.

SOUZA, C. R. de. "Os Pioneiros do Cinema Brasileiro". Alceu. Rio de Janeiro, vol.8, n 15, p. 20 -

37, julho-dezembro de 2007.

TINHORÃO, J. R. Música Popular: teatro e cinema. Petrópolis: Vozes, 1972.

História Social da Música Popular Brasileira. São Paulo: Editora 34,

1998.

VIANNA, H. O Mistério do Samba. Rio de Janeiro: Zahar/UFRJ, 1995.

Bases de dados:

HEMEROTECA DIGITAL BRASILEIRA. Base de dados da Fundação Biblioteca Nacional. Disponível em < http://hemerotecadigital.bn.br $>$. Acesso em 09 ago. 2015.

INSTITUTO MOREIRA SALLES. Base de dados. Disponível em < http://acervo. ims.com.br >. Acesso em 09 ago. 2015.

\section{Fonogramas:}

ABREU, Zequinha (compositor) com Orquestra Colbaz. Tico-tico no fubá. São Paulo: Columbia, 1931, 78 rpm, lado A, no 55038.


(interprete) com Orquestra Columbia. Juracy. São Paulo: Columbia, 1931, 78 rpm, $n^{\circ} 22002$.

CARVALHO, Helena Pinto de (intérprete). Esse jeitinho que você tem. São Paulo: Columbia, 1931, 78 rpm, lado A, nº 22054.

JARARACA (intérprete e compositor) e RATINHO (intérprete e compositor). Côco do mato. São Paulo: Columbia, 1930, 78 rpm, lado A, no 5146.

JARARACA (intérprete e compositor) e RATINHO (intérprete e compositor). Cadê tempo. São Paulo: Columbia, 1930, 78 rpm, lado B, no 5146. 
LARA, Zezé (intérprete). Tarde sertaneja. São Paulo: Columbia, 1931, 78 rpm, nº 22053.

MACEDO, Stefana (intérprete). Batuque. São Paulo: Columbia, 1929, 78 rpm, lado A, no 5093.

MACEDO, Stefana (intérprete). Bambalelê. São Paulo: Columbia, 1929, 78 rpm, lado $\mathrm{B}, \mathrm{n}^{\circ} 5093$.

PARAGUAÇU (intérprete). Nunca mais. São Paulo: Columbia, 1929, 78 rpm, nº 5091.

REDONDO, Jaime (intérprete) com Trio Ghiraldini. Saudades. São Paulo: Columbia, 1929, 78 rpm, lado B, no 5027.

\section{Revistas e jornais:}

Correio da manhã. Rio de Janeiro, 27 de novembro de 1931.

Jornal do Brasil. Rio de Janeiro, 01 de dezembro de 1931.

Variety. New York, 01 de setembro de 1922.

submetido em: 09092015 | aprovado em: 10112015. 